These resources include, geothermal energy, hydroelectric power, solar energy, wind energy, biomass, tidal and wave power. Energy is a very important tool daily residential, industrial and economic activity. Affordable and reliable energy sources are the key objectives of any government to provide cheap energy to its people. This paper reports on the possible hybridization of the parabolic solar plant with a biogas plant.

\section{PRESENT WORK}

The site proposed for hybrid power generation is village situated in Punjab. The total population of the village is 3900 . In the village, raw material for biomass power plant can be made available. The total number of cattle in the village is 2340 . In the village has abundant quantity of human waste and animal dung, which can be used to generate electricity by installing biogas power plant. Average solar radiation at the village is $4.73 \mathrm{kWh} / \mathrm{m} 2 /$ day, therefore the site has also a great potential to generate electricity through solar power plant. Three project models, one is of biomass power plant of $1000 \mathrm{~kW}$, second is of biogas power plant of $350 \mathrm{~kW}$ capacity and the last is of solar power plant of $400 \mathrm{~kW}$ capacity are hence proposed.

\section{METHODOLOGY}

\subsection{Photovoltaic system}

Sizing a photovoltaic system is an important task in the system"s design. In the sizing process one has to take into account three basic factors: i. The solar insolation of the site and generally the Metrological data ii. The daily power consumption (Wh) and types of the electric loads, and iii. The storage system to contribute to the system "s energy independence for a certain period of time The PV generator is oversized it will have a big impact in the final cost and the price of the power produced and in the other hand, the PVgenerator is undersized, problems might occur in meeting the power demand at any time. The sizing should be carefully planned, examining various possible PV system configurations and various models of components in order to get a cost effective and reliable system [3]. Theamount of solar radiation at a site at any time, either it is expressed as solar intensity $(\mathrm{W} / \mathrm{m} 2)$ or solar insolation or radiation in MJ or $\mathrm{Wh}$, is primarily required to provide answer to the amount of power produced by the PV generator. The amount of electrical energy produced by a PV-array depends primarily on the insolation at a given location and time. Data on solar insolation are usually given in the form of global radiation that is beam, direct and diffuse radiation over a horizontal surface.

\subsubsection{SYSTEM COMPONENTS}

In this analysis, the major components are PV panels, biogas disaster, bio fuel generators, batteries, and converters. For economic analysis, the number of units to be used, capital cost, replacement and O\&M costs and operating hours to be defined in HOMER in order to simulate the system.

\subsubsection{Solar Photovoltaic;-}

Sun rays are available with prosperity in Barisal, Bangladesh. Lots of solar home system has been installed. But, there is no set up yet established for off grid networking. In this research, solar photovoltaic is used with biogas generation for the establishment of a hybrid system. Solar system cost consists of cost with cables and charge controllers. It's known to me by analysing present market; cost of PV panel with set up cost Tk. 75000 for $1 \mathrm{~kW}$ generation. Various costs are represented in Table 1 and cost is considered in BDT. Life time has been taken 25 years.

\subsubsection{Generator}

In this research, two set of $10 \mathrm{~kW}$ biomass generators are considered to find out the most cost effective system. The main reason of using to fulfil the energy demand in peak hour both for winter and summer season and also meet the terms of backup requirements. As biomass resource is available in prosperity, fuel cost is considered zero. The main cost is considered for biogas generation procedure and biogas power generator. . To produce $1 \mathrm{KW}$ electricity from biomass, $\$ 1200$ is required including plant cost and generator cost, i.e. about BDT 9600000 is required in this purpose. Digester lifetime is considered for 8 years and fuel curve slope and intercept are taken as 0.05 and 0.33 respectively.

\subsubsection{Battery}

Batteries are used to store the solar photovoltaic output. In rural area like our proposed are, where most of the power is used after day time. So, main target of our system is to store energy at day time and discharge the stored energy after evening. So, batteries are used following through charge controller. Also, a dump load is used for the purpose of removing excess charge and preventing system damage. In this 
system, the Surrette $4 \mathrm{KS} 25 \mathrm{P}$ storage batteries are utilized. The specifications and different costs of batteries.

\subsubsection{Converter}

Converter converts the dc power to ac power. As, most of the home appliances are operated in ac, dc generation from the PV array is converted to ac following through a controller. In this .proposed system, $25 \mathrm{~kW}$ converters are considered for optimum solution. The details of converter cost assumption and different parameters.

\subsection{Biomass power}

Biomass power: Biomass is the amount of living matter in a given habitat, expressed either as the weight of organisms per unit area. Biogas is a mixture of gases, generally carbon dioxide and methane. It is produced by microorganisms, especially in the absence of oxygen. This process is called anaerobic process. Biogas also can develop at the bottom of lakes where decaying organic matter builds up under wet and anaerobic conditions. And a biodiesel is made from vegetable oils and animal fats. The main factor of choosing this type of hybrid system consist of biomass is that in remote area villages it is easily and economically available in the form of dung of cow, buffalo, goat etc. During the cloudy day, the total electricity production can depend on the biomass. The most perspective was the building of biogas plant in a remote area and care has to be taken that, as there was located large dairy farm. Rest of the needed feedstock for this cogeneration plant is provided by plant biomass, e.g. cereals, perennial grasses, maize, other energy crops or biomass from unused agricultural areas. It is recommended to include in feedstock, a part of manure, the different local biomass, e.g. maize, perennial grasses and legumes, straw, reed, waste biomass from food industry, biodegradable part of municipal wastes, aiming to increase economical viability for potential biogas projects and to provide stable round year running of biogas cogeneration plants.

\section{COMBINED BIOMASS BIOGAS AND SOLAR PV SYSTEM}

A PV - Biomass power system, which is a combination of a photovoltaic array integrated with a biomass generator, is a better option for a remote area which is not connected to the grid and is a best solution to electrification of remote areas, where extension of national grid is not a cost effective option. The system which is analyzing consists of a PV array, a battery bank, a biomass generator, a charge controller and a DC/AC converter. In the design and sizing of the system; the system should be considered as an autonomous system. Such a constraint leads to an infinite number of possible system configurations In the first step we will collect the data regarding location of area, the total land area, area under crops, crop production, energy consumption, agri-residue output, raw material available, average radiation per square meter, sunshine hours per year etc and second step calculate load of the selected village. The next step will be proper selection of equipments (Engines, generators, turbines, boilers, types of engines, effect of temperature, digester design, height of digester, batteries, inverter, PV collectors, cables etc.) [3]. Next step Cost estimations (Subsidies by government and private bodies, generation cost etc). At last step we will calculate of payback period. Finally the whole area will be supplied power with the help of Micro Hybrid biomass, biogas and solar combined power plant.

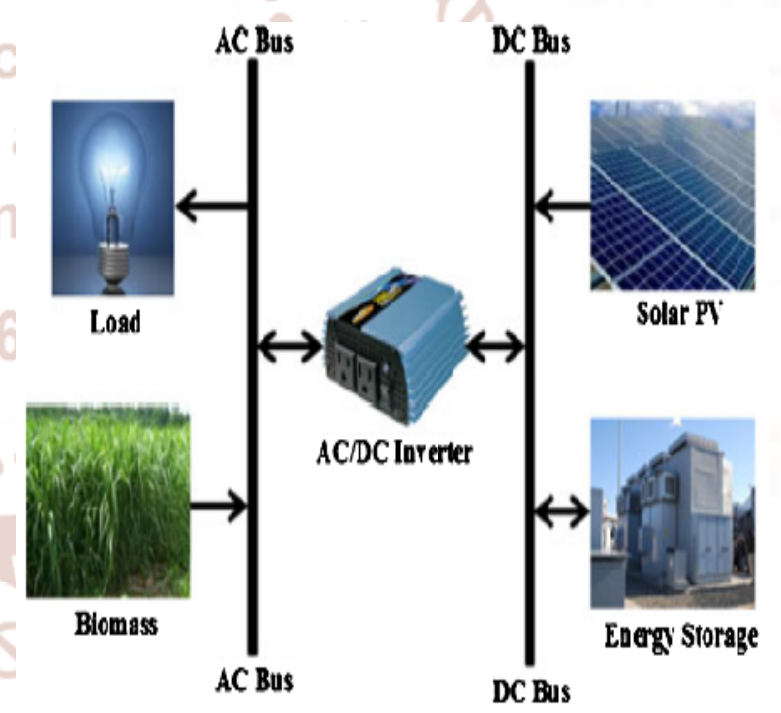

Figure 1 Block diagram of Hybrid Power Plant

\section{PROJECT MANAGEMENT}

Project management is applying knowledge, skills, tools and techniques into project activities to meet project requirements. It is accomplished through rational use and integration of 42 project management processes. According to their logic theories, the process can be categorized into five process groups: initiating, planning, implementing, monitoring and 
ending. This article will identify the five process groups respectively.

\subsection{Initiating Process}

The main task of this phase is to determine the project charter. To reduce the uncertainty in project implementation, project charter should include the following areas: clear objectives, initial scope, preliminary budget, project manager power distribution, major project stakeholders.

\subsection{Planning Process}

In the planning process, it is essential to make a detailed plan on the schedule, cost and risk and communication, scope quality in the process of establishment of the raw material purchasing system, which are finally summarized into concrete implementing scheme and project documents.

\subsection{Implementing Process}

The main task of this phase is to perform all kinds of tasks and goals at the planning stage so as to ensure the implementation of purchasing task. At this stage, we should pay attention to the following questions: The pretreatment of the raw material. Biomass raw materials is essentially characteristic of low energy destiny and bulk mass. In order to reduce the cost of material transportation, the materials need to/be preprocessed.

\section{RESULT AND DISCUSSION}

The assumptions made on the conversion equivalents of biomass are as follows; Biogas contains 65\% methane, which when burnt produces $35 \%$ electrical power, $50 \%$ heat and $15 \%$ goes to losses.For the calculation of the amount of electricity and heat obtained per day it is assumed that 1 tonne $=300 \mathrm{~m} 3$ of biogas . Table II shows the demand of electricity expressed in terms of equivalent heat versus the electricity generation from the CSP plant. Assuming electrical conversion efficiency of $35 \%$, for every $1 \mathrm{~m} 3$ of biogas we obtain $2.14 \mathrm{kWh}$ (electricity), $3.96 \mathrm{kWh}$ of thermal heat. For the month of January the daily average of electricity and heat was calculated to be: Electricity per hour in one day in January from biogas was $3940.8 \mathrm{kWh}$, thermal heat in one day in January from biogas $(\mathrm{H} 3)$ is calculated as $5629 \mathrm{kWh}$.

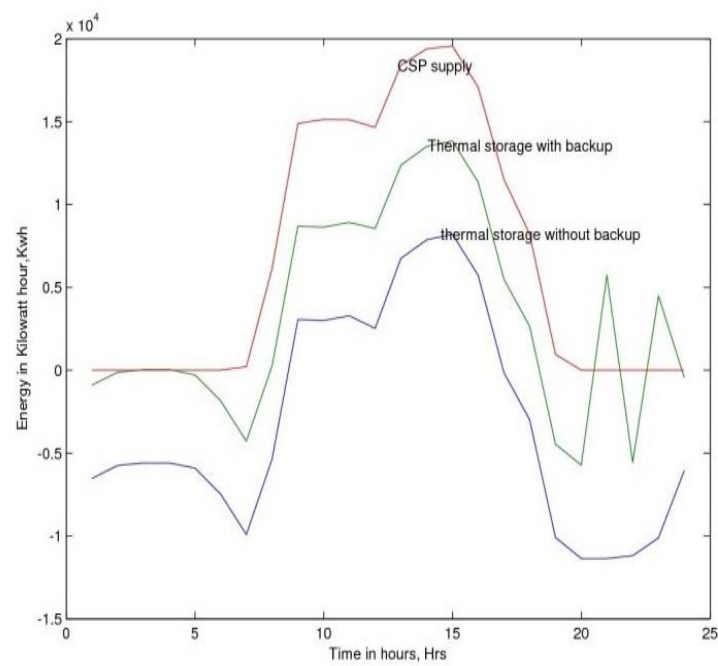

Fig 2: Graph of electricity generation and storage in a day

\section{CONCLUSION}

In many spots of the world the sun isn't there for 24 hrs henceforth to take care of the expanding demand at any given time we have to supplement the illustrative trough stockpiling with some warmth prepared for dispatch in overcast days or around evening time. The utilization of anaerobic absorption brings down the discharge of the Green house gases fundamentally. Age of power utilizing the waste warmth as a reinforcement radiator for the warm stockpiling of the allegorical plant expands the measure of vitality stockpiling for sometime later and subsequently it upgrades dependability of the plant. This arrangement gives a higher electric power generation and a noteworthy solidness of the warm framework and in addition making a higher inexhaustible yield of the plant. Hybridization of a CSP plant with biomass plant can be an answer for the debilitated vitality emergency in numerous African people group who still depends on kindling for their day by day vitality in cooking and lighting. Innovative work ought to be done to think of a warmth exchange liquid that will have the capacity to store the warm vitality from the sun for constant age after nightfall. Concentrating sun oriented warm power can is an inexhaustible type of power age. It doesn't radiate the green house gases which is one of its prime points of interest. 


\section{REFERENCES}

1. P.Frebourg, N.Ketjoy, S. Nathakaranakul, A.Pongtornkulpanich, W. Rakwichian, P. Laodee, "Feasibility Study of a Small-Scale GridConnected Solar Parabolic Biomass Hybrid Power Plant in Thailand".PP 1-5.

2. N. D. KAUSHIKA*, A. Mishra, M. N. Chakravarty, "Thermal analysis of solar biomass hybrid co-generation plants", International Journal of Sustainable Energy, Vol. 24, No. 4, December 2005, 175-186.

3. E. De Tuglie,M.Dicorato, G.Forte, M. Pisani, "One-axis tracking optimization of Concentrating Solar Power plant for electricity production",pp 16, Sept 2010

4. A.D.cuellar,M.e.Webber, "Cow Power: The energy and emissions benefits of converting manure to biogas",pp1-8,24th July 2008.

5. C. Banks, "Optimising anaerobic Digestion", 25th March 2009.

6. Bauen, Ausilio, et al. "Bioenergy: a sustainable and reliable energy source. A review of status and prospects." Bioenergy: a sustainable and reliable energy source. A review of status and prospects, 2009

7. Ying, Li, and Li Jing. "Study on Calculation Method of Carbon Emission in Power Generation with Biomass." Environmental Science and Management 3,2012

8. Guide, A. "Project Management Body of Knowledge (PMBOK ${ }^{\circledR} \quad$ GUIDE)." $\quad$ Project Management Institute,2001

9. Loeser, M. and Redfern, M.A., Micro-Scale Biomass Generation Plant Technology: StandAlone Designs for Remote Customers, in 16th European Biomass Conference \& Exhibition (EBCE). 2008, ETAFlorence: 2-6 June 2008, Valencia, Spain. p. 1468-1477.

10. Loeser, M. and Redfern, M.A., Modelling and simulation of a novel micro-scale combined feedstock biomass generation plant for gridindependent power supply. International Journal of Energy Research, 2009. 9999(9999): p. n/a.

11. Loeser, M. and Redfern, M.A., Novel Combined Feedstock Micro-Scale Biomass Generation Plant for Remote Power Supply - Modelling and Simulation Results, in 17th European Biomass Conference \& Exhibition (EBCE). 2009, ETAFlorence: 29 June 3 July 2009, Hamburg, Germany.

12. Bain, R.L., An overview of biomass combined heat and power technologies, in 2004 IEEE. 